\title{
The Role of Punch Grafting in Eyebrow Replacement
}

\author{
D. A. RANNEY* \\ Schieffelin Leprosy Research Sanatorium, \\ Karigiri, S. India
}

\begin{abstract}
Many techniques of eyebrow replacement are now available, each with its own advantages and disadvantages. For complete replacement of eyebrows punch grafting has no particular advantage. However it can be recommended for restoring hair to the important medial end of an otherwise successful vascular island transfer in anyone distressed by hair loss in this area. Important technical details are described.
\end{abstract}

Many methods of eyebrow reconstruction have been advocated. Droogenbroeck (1971) has listed these as:

(1) Transplantation of small islets from the scalp.

(2) Transposition of scalp flap without artery pedicle (Antia, 1964).

(3) Temporal artery island scalp flap described by Brand (Antia, 1964).

(4) Free graft of scalp described by Gillies (Fritschi, 1971).

(5) Single hair transplant method of Arakaw (1967) otherwise known as the rice-planting technique.

$\mathrm{He}$ then goes on to describe the latter method in detail as practised by Kanazashi (Droogenbroeck, 1971). No one would deny that the technique of single hair transplantation can give cosmetically excellent results. But the transplantation of 280 individual hair follicles in two $2^{1 / 2} \mathrm{~h}$ sessions must be very tedious indeed. One can have nothing but admiration for the patience and skill of those who would devote so much effort to so worthy a cause.

At the other extreme free grafting is the easiest and least time consuming method of replacing lost eyebrows. It can give a good growth of hair, a little less luxuriant perhaps than the vascular island transfer but in societies where eyebrows are not normally bushy a quite adequate result. Great care must be taken to defat the graft but it must not be excessively defatted or the germinative cells which lie at the very bottom of each hair follicle will be lost. The chief advantage of the technique is that the transplant used can be so aligned as to allow the hairs to be directed in a natural direction.

* At present, Assistant Professor of Anatomy, and Clinical Assistant, Department of Surgery, Queens University, Kingston, Ontario, Canada. 


\section{The Value of the Island Transfer}

At the Schieffelin Leprosy Research Sanatorium we have preferred the vascular island transfer based on the temporal artery. When correctly performed it usually gives a luxuriant growth of hair. This bushy growth is preferred in India as eyebrows are normally bushy here and also because those who have feared ostracisation or contempt due to loss of eyebrows now have no doubt of their acceptance by society. There is a second and equally valid reason for continuing the use of the vascular island transfer. By teaching the technique the surgical trainees here learn the importance of gentle handling of tissues. Then when sufficient skill has been developed with this technique the surgeon can turn his hand to the valuable but somewhat more hazardous task of restoring sensation in partially anaesthetic hands by means of a neuro-vascular island transfer (Lennox and Ranney, 1973).

\section{Problems With the Island Transfer}

The island transfer may rarely fail completely. During dissection, unless sufficient care is taken, the temporal artery may be inadvertently severed. If so, the island should be defatted and transferred as a free graft. This is particularly unfortunate if a successful vascular island transfer has already been done on the other side because there may be diminished hair growth on the free grafted side.

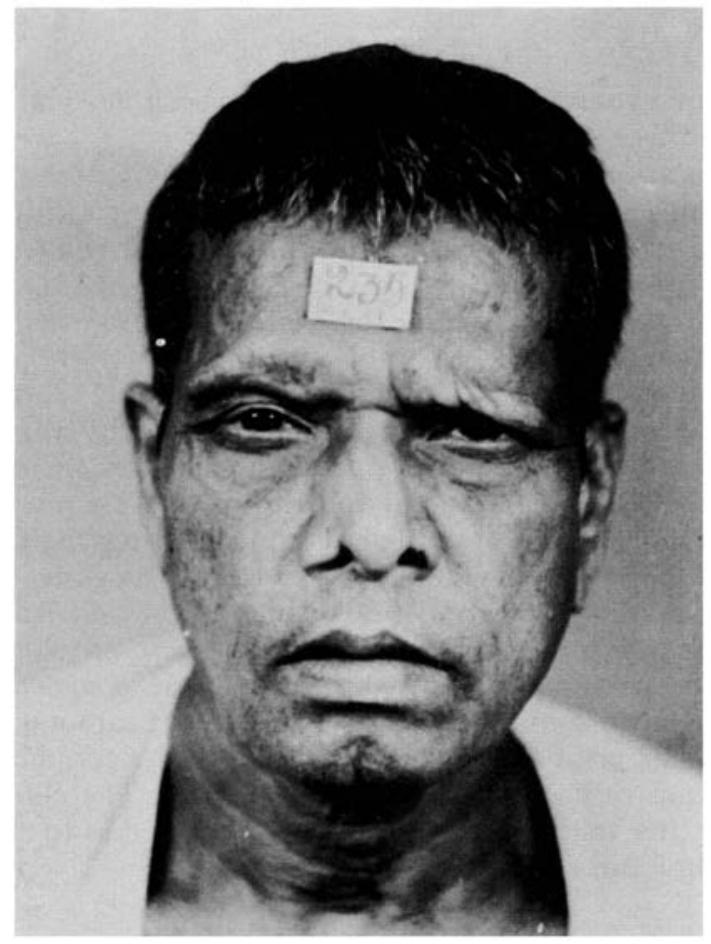

Fig. 1. The appearance of bilateral failure of eyebrow after failed temporal artery island scalp flap. 
Post-operative hematoma or infection may also diminish or completely abolish hair growth. Hypertension and arterial vascular disease may reduce the chance of a successful transfer and are relative contraindications. Sometimes the cause of a poor result is unknown. Tortuosity of the temporal artery may be so great as to make it necessary to transfer a wide island which can later be reduced in width. Otherwise the most important more medial end of the transfer may be hairless. This complication is therefore preventable by carefully marking out the course of the artery with gentian violet pre-operatively. This may require exercises and therefore should be done before premedication is given. Then the island transferred is made wide enough to include the artery, and trimmed 3 months later. All these complications are usually preventable by good surgery and proper selection of cases.

The most distressing problem for which there has seemed no solution arises when the branch of the temporal artery chosen breaks up into a mass of little branches before reaching the medial end of the proposed eyebrow transfer. The possibility of punch grafting this end, using the same method as is used for scalp replacement, was considered (Orentreich, 1971). But before this could be tried a patient presented who had had a total failure of the island transfer on the right side and therefore refused a similar procedure on the left (Fig. 1). We could not guarantee the free graft would produce the generous amount of hair that we expected from a successful vascular island transfer on the other side, therefore

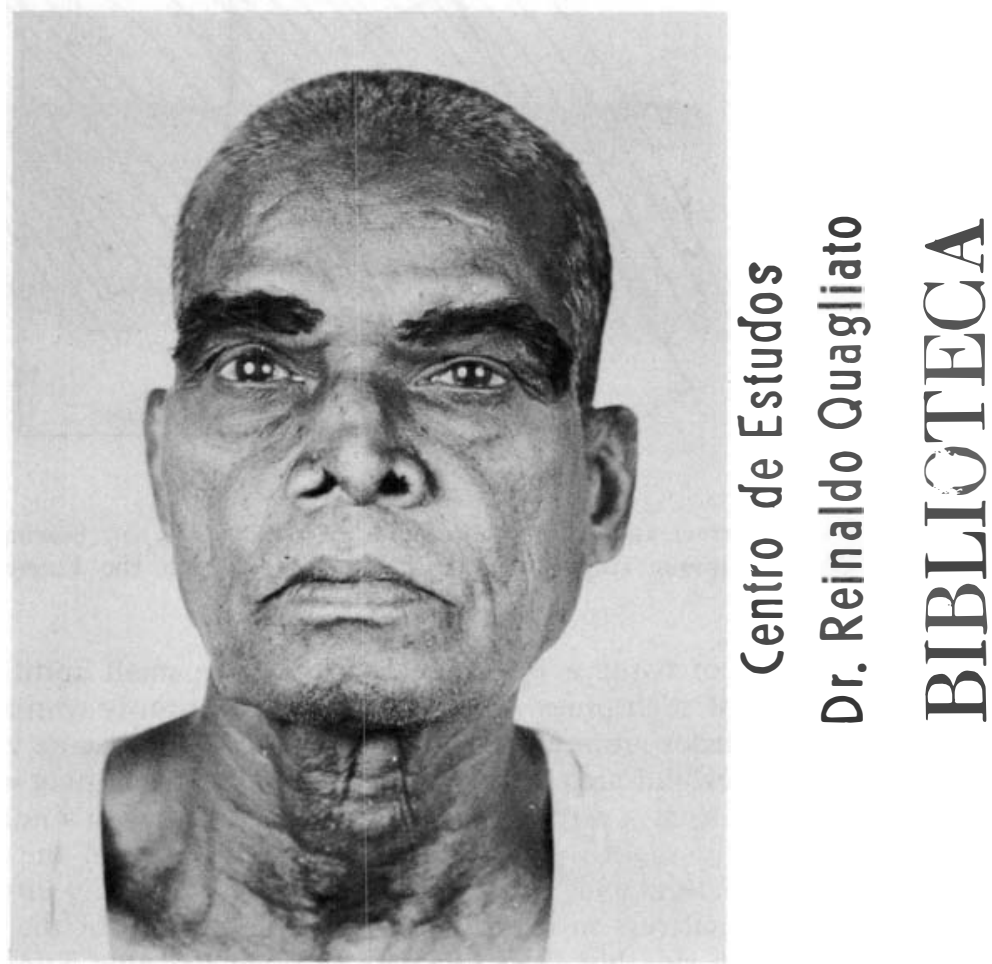

Fig. 2. The same patient 4 months after eyebrow replacement by the punch grafting method. 
punch grafting was performed on the right at the same time as the contralateral vascular island transfer. The island in this case also failed to produce any hair at all for no apparent reason although the technique was flawlessly performed and no other cause of failure could be found. The punch grafting also failed because the punch was not inserted at the correct angle (see below). Subsequent punch grafting was correctly done bilaterally with a good result (Fig. 2). Since then this technique has been used for other cases to enhance the growth at the medial end of a vascular island transfer.

\section{The Technique of Punch Grafting}

The technique of punch grafting is not very difficult but certain principles must be carefully observed. The donor area must be one which promises continued hair production if baldness later should occur since the transferred hairs will survive in their new site just as long as in their original site, but no longer. Usually the occipital area is best. The hair is clipped short, about $1 / 4 \mathrm{in}$. The direction of the hairs is noted and a $5 \mathrm{~mm}$ diameter skin biopsy punch is inserted into the scalp parallel to the shafts of the hairs (Fig. 3). By rotating while applying gentle

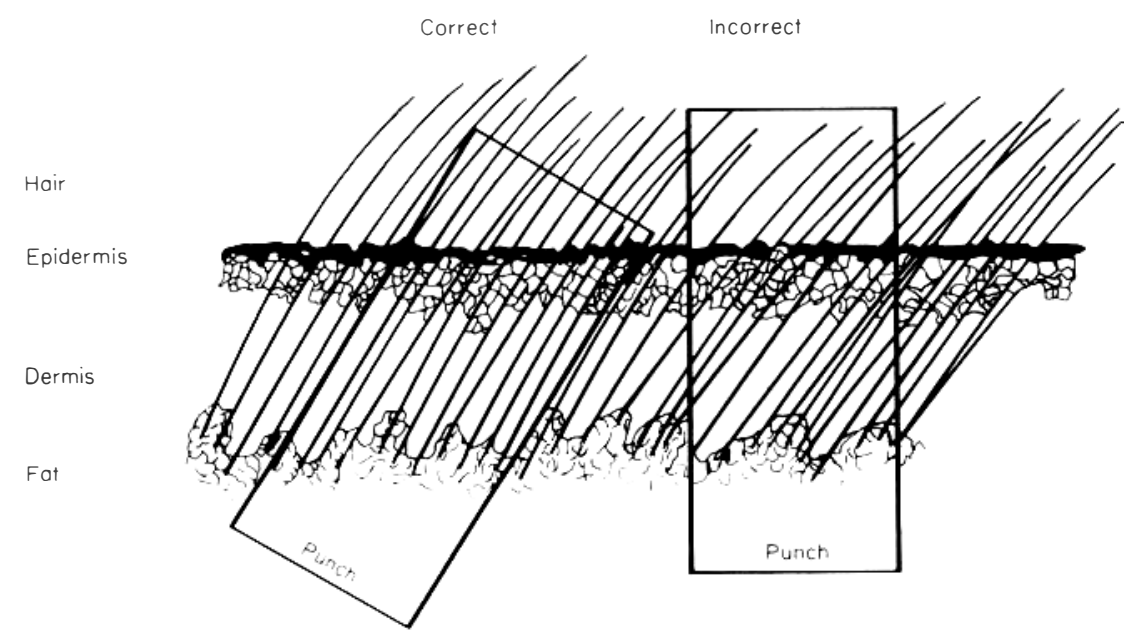

Fig. 3. The correct and incorrect methods of removal of hair bearing scalp tissue by the punch graft technique (reproduced with permission from the Surgical Clinics of North America).

pressure a plug of tissue is isolated. Occasionally a small knife is needed to sever the fatty base of such plugs. The excess fat is cautiously trimmed until the bases of the hair follicles are seen but not damaged. A $4 \mathrm{~mm}$ core of skin is removed from the supraorbital area at the same angle as the $5 \mathrm{~mm}$ plug which has been cut and directed in such a way as to allow the hairs to grow in a normal direction, i.e. upward and only slightly laterally if at the medial end of the eyebrow area and laterally at the lateral end. Usually a $5 \mathrm{~mm}$ plug fits securely into a $4 \mathrm{~mm}$ hole but occasionally a mattress suture is necessary over the top of the plug which enters the skin on each side but does not pass through the plug. Similarly smaller plugs may be used between the larger plugs to give a more even appearance and $4 \mathrm{~mm}$ 


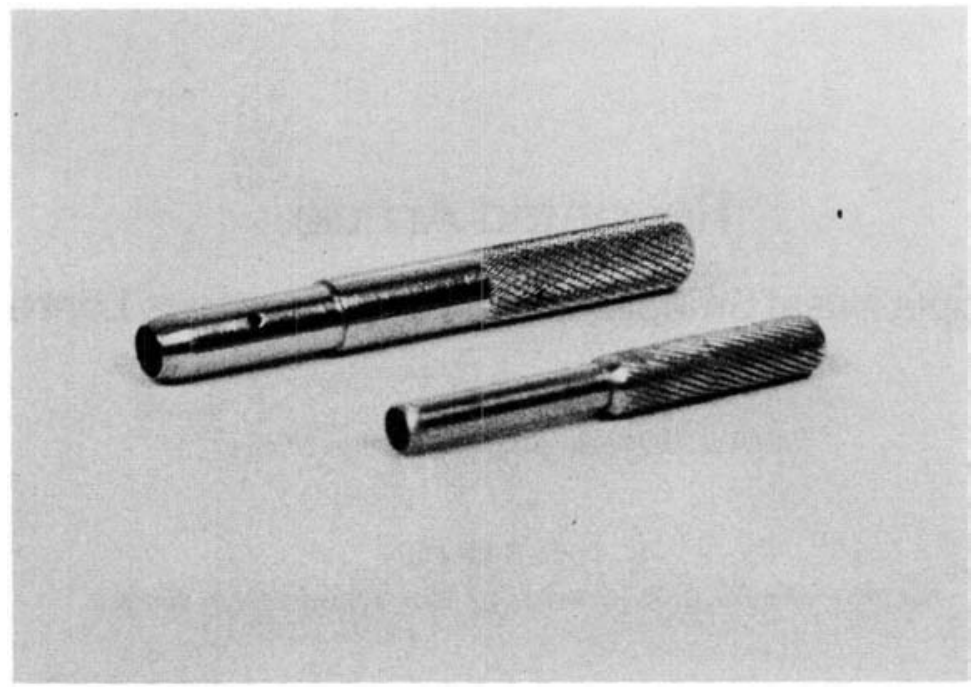

Fig. 4. Two different sizes of skin punch.

diameter plugs are inserted into $3 \mathrm{~mm}$ diameter holes. A moist saline dressing is applied and removed on the 5 th day by which time the area is healed. The donor area is dressed with vaseline gauze. The healing here takes a little longer but time can be shortened by suturing the holes shut. The initial hair of ten falls out and the final appearance is best seen at 3 months.

\section{A Suggested Role of Punch Grafting in Eyebrow Replacement}

Eyebrows can be completely replaced by the technique of punch grafting as is usually practised in scalp hair replacement.* However the operation is tedious and for total eyebrow replacement a vascular island transfer or free graft is preferable. However punch grafting can be useful in "touching up" the medial end of an otherwise successful vascular island transfer.

\section{References}

Antia, N. H. (1964). The eyebrows. In Leprosy in Theory and Practice, (R. G. Cochrane, T. F. Davey, eds). Bristol: John Wright and Sons.

Arakawa, I. (1967). Eyebrow-plasty with single-hair transplant for alopecia leprosa. La Leproa 36, 218-224. (In Japanese, English Summary). Abstracted in Int. J. Lepr. 36, (1968), 476.

Droogenbroeck, Van J. B. A. (1971). Eyebrow transplantation. Int. J . Lepr. 39, 629-630.

Fritschi, E. P. (1971). Reconstructive Surgery in Leprosy. Bristol: John Wright and Sons, Ltd., pp. $116-119$.

Lennox, W. M. and Ranney, D. A. (1973). The value of neurovascular island transfers in partially anaesthetic hands. Paper read at the Tenth International Leprosy Congress, Bergen.

Orentreich, N. (1971). Hair transplantation; the punch graft technique. Surgical Clinics of North A merica 51, 511-518.

* Since submitting this for publication the author has noted Watson et al., to be also using this technique successfully. [Watson, P. E., Little, Jr. W. D. and Fields, J. P. (1970). Treatment of eyebrow loss with punch hair transplants. Cutis 6, 176-178.] 